\title{
UJI EKSPERIMEN STABILISASI TANAH DASAR DENGAN SEMEN PADA RUAS JALAN MALAWILI DISTRIK AIMAS KABUPATEN SORONG
}

\author{
Rokhman Rokhman ${ }^{1}$, Hendrik Pristianto ${ }^{2 *}$, Anisari Lingara ${ }^{3}$ \\ ${ }^{1,2}$ Dosen Program Studi Teknik Sipil Universitas Muhammadiyah Sorong \\ ${ }^{3}$ Mahasiswa Program Studi Teknik Sipil Universitas Muhammadiyah Sorong \\ Jln. Pendidikan No 27 Kota Sorong, Papua Barat \\ *tekniksipilsorong@gmail.com
}

\begin{abstract}
Abstrak
Kerusakan pada konstruksi perkerasan jalan disebabkan oleh banyak faktor. Selain beban-beban kendaraan, kondisi tanah dasar yang kurang baik juga mempunyai pengaruh terhadap kerusakan yang terjadi. Beberapa ruas jalan di Kabupaten Sorong mengalami kerusakan dan hal ini perlu dicari alternatif solusinya. Salah satunya adalah di ruas jalan yang berada pada wilayah Distrik Aimas Kabupaten Sorong Propinsi Papua Barat. Tujuan penelitian ini adalah untuk mengetahui sifat fisik dan teknis tanah dasar di ruas jalan Distrik Aimas Kabupaten Sorong sebelum dan sesudah distabilisasi dengan semen serta pengaruhnya terhadap nilai CBR. Alternatif stabilisasi tanah dasar dengan semen merupakan salah satu solusi dalam upaya peningkatan kualitas tanah dasar untuk konstruksi perkerasan pada ruas jalan di Kabupaten Sorong. Pengujian stabilisasi tanah ini menggunakan semen sebagai bahan stabilisasi. Presentase semen yang digunakan adalah 7\%. Hasil penelitian menunjukan bahwa nilai CBR, dan kepadatan standar naik dengan naiknya presentasi semen didalam tanah. Pada kadar semen tersebut terlihat adanya penurunan potensi pengembangan dan peningkatan nilai CBR yang cukup signifikan. Pada pengujian tekan bebas terlihat bahwa semakin tinggi kadar semen, nilai parameter kuat geser tanah semakin naik. Dimana nilai CBR tanah asli sebesar 1,62\% terjadi peningkatan nilai CBR pada pencampuran optimum $7 \%$ semen dengan waktu pemeraman 3 hari dengan nilai CBR 3,76\%.
\end{abstract}

Kata Kunci : Stabilisasi, Subgrade, Semen

\section{PENDAHULUAN \\ Latar Belakang}

Kegagalan pada konstruksi jalan banyak faktor yang mempengaruhi, ketidakcermatan dan ketelitian terhadap syarat batas yang diijinkan dari berbagai macam material lapisan perkerasan jalan akan mempercepat terjadinyakerusakan jalan. Kegagalan subgrade (subgrade failure) sering banyak dijumpai pada pembangunan maupun rehabilitasi jalan, stabilisasi tanah pada subgrade adalah untuk memperbaiki bahan-bahan lokal jalan yang tersedia dengan memberikan bahan tambahan yang sesuai, semen pada umumnya akan dapat mengurangi bahkan akan menghilangkan masalah-masalah yang ada. Untuk pondasi jalan yang menggunakan stabilisasi tanah-semen di Indonesia sudah banyak dilakukan. Atas dasar itu, guna memperoleh pendekatan penanganan pada kegagalan subgrade (subgrade failure) yang terjadi khususnya pada ruas jalan Malawili Kabupaten Aimas, dengan menggunakan stabilisasi tanah-semen sampai sejauh mana pengaruhnya terhadap kembang susut dan daya dukungnya. Sub grade atau tanah dasar merupakan fondasi yang menopang beban perkerasan yang berasal dari kendaraan yang melewati suatu jalan, oleh karena itu perencanaan suatu perkerasan jalan sangat di tentukan oleh kondisi tanah dasar (sub grade ).

Permasalahan yang sering timbul adalah sub grade memiliki daya dukung tanah (California Bearing Ratio $=\mathrm{CBR}$ ) rendah dan kembang susut yang tinggi sehingga terjadi keruntuhan lokal tanah pada musim hujan. Permasalahan ini sering dijumpai pada saat pembangunan perkerasan jalan di atas tanah lempung lunak. Departemen Pekerjaan Umum mensyaratkan bahwa nilai California Bearing Ratio (CBR) pada kondisi terendam air dari suatu sub grade minimal $5 \%$ dan nilai Indeks plastisitas tanah harus kurang dari $15 \%$.

\section{Tujuan Penelitian}

Tujuan dari penelitian ini adalah :

1. Untuk mengetahui sifat fisik dan teknis tanah dasar pada ruas jalan di wilayah Malawili

Distrik Aimas Kabupaten Sorong sebelum dan sesudah di stabilisasi dengan semen. 
2. Untuk mengetahui pengaruh penambahan semen terhadap nilai CBR tanah dasar pada ruas jalan di wilayah Malawili Distrik Aimas Kabupaten Sorong.

\section{METODOLOGI}

\section{Lokasi Penelitian}

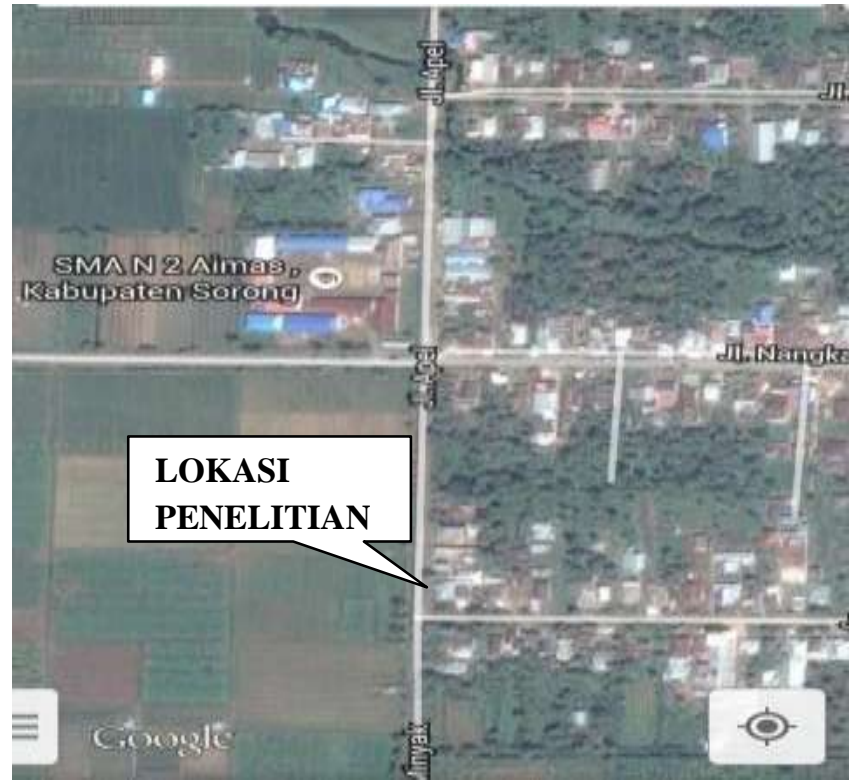

Gambar 1. Lokasi Pengambilan Sampel Tanah

\section{Ruang Lingkup Penelitian}

Agar penelitian ini terfokus dan tidak melebar maka perlu adanya batasan yang perlu diperhatikan dalam studi ini antara lain :

1. Pengujian laboratorium untuk menetukan sifat fisik tanah atau jenis dan kondisi tanah (index properties) sebelum dan sesudah dicampur dengan semen, penelitian ini hanya membahas menganai beberapa faktor yang berpengaruh pada kinerja ruas jalan yang terdapat di jalan Malawili Kabupaten Sorong depan SMA Negeri 2 Aimas.

2. Penelitian ini dilakukan selama 14 hari yakni tanggal 24 Januari sampai dengan 6 Februari 2017 di Laboratorium kampus Universitas Muhammadiyah Sorong, menggunakan sampel tanah $20 \mathrm{~kg}$ dan semen tonasa (Portland) $1 \mathrm{~kg}$ sampel tanah diambil dari tanah dasar (subgrade) yang terdapat di jalan Malawili Distrik Aimas Kabupaten Sorong depan SMA Negeri 2 Aimas.

\section{Bahan dan Alat Penelitian}

Bahan dan peralatan yang diapakai dalam penelitian ini adalah :

1. 1 set peralatan uji analisa saringan

2. 1 set peralatan uji CBR

3. Sampel tanah dari lokasi studi

4. Air

\section{Prosedur Penelitian}

Tahapan dan prosedur penelitan adalah dengan melakukan serangkaian pengujian sampel tanah asli dari lapangan. Adapun beberapa pengujian yang dilakukan terhadap sampel tanah adalah :

1. Pengujian Berat Jenis Tanah

2. Pengujian Batas-Batas Atterberg

3. Pengujian Analisa Saringan

4. Pengujian Analisa Hidrometer

5. Pengujian Pemadatan /Compaction

6. Pengujian CBR tanah asli

7. Pengujian CBR tanah+semen

Teknik Pengolahan dan Analisis Data 
1. Penelitian ini dilakukan dengan metode eksperimental di laboratorium. Pekerjaan eksperimental dimulai dengan melakukan persiapan tanah yang diambil dari tanah asli dan pengadaan bahan stabilisasi yaitu semen. Setelah tanah dan bahan sudah siap dilanjutkan dengan penelitian tanah asli meliputi penelitian sifat fisik tanah asli dan sifat mekasik tanah asli dengan menggunakan Standar Nasional (1994). Tata cara pembuatan stabilisasi tanah dengan semen porland untuk jalan (SNI 03-3438-1994).

2. Kemudian dilanjutkan penelitian tanah yang distabilisasi dengan langkah awal menentukan komposisi campuran tanah dengan bahan stabilisasi dilanjutkan dengan prosedur pembuatan benda uji, benda uji yang telah diperam sesuai dengan umur pemeraman diteliti kinerjanya dengan Pengujian CBR bertujuan untuk menentukan kekokohan permukaan lapisan tanah yang umumnya akan dipakai sebagai sub-base (urugan) atau sub-grade (lapisan tanah dasar) konstruksi jalan. Satu hal yang perlu diingat bahwa pengujian CBR hanya mengukur kekokohan relatif dari lapisan permukaan tanah, karena diameter penampang torak yang dipergunakan hanya sekitar $4.96 \mathrm{~cm}$, sehingga daerah (volume) lapisan tanah dibawah torak yang terpengaruh tekanan (stress bulb) hanya di permukaan.

\section{HASIL DAN PEMBAHASAN}

\section{Hasil Pengujian Laboratorium}

A. Pengujian Berat Jenis

Pemeriksaan ini dimaksudkan agar dapat mengetahui cara menetukan berat jenis tanah dengan menggunakan labu ukur (piknometer). Tujuan dari pemeriksaan ini yaitu mentukan berat jenis tanah.

Tabel 1. Berat Jenis Sampel Tanah Yang Diuji

\begin{tabular}{ccc}
\hline Nomor Percobaan & I & II \\
\hline Berat Piknometer W $($ gram $)$ & 76.9 & 76.78 \\
Berat Piknometer + air, W $\mathrm{W}_{2}($ gram $)$ & 176.64 & 177.51 \\
Berat Piknometer + air + tanah, W $($ gram $)$ & 187,99 & 189.83 \\
Temperatur, T $\left({ }^{\circ} \mathrm{C}\right)$ & 29 & 29 \\
Berat jenis tanah & 1,1258 & 1,1367 \\
Berat jenis tanah (rerata) & \multicolumn{2}{c}{1,1313} \\
\hline
\end{tabular}

B. Pemeriksaan Batas Batas Atterberg

Sumber : Hasil Perhitungan

Pemeriksaan ini dimaksudkan untuk mengklasifikasi serta memastikan karakter indeks property tanah, yang mencakup batas cair-batas plastis dan batas susut.

Tabel 2. Batas Cair Tanah Yang Diuji

\begin{tabular}{lcccc}
\hline NO.Test & & 1 & 2 & 3 \\
Jumlah Pukulan & & 14 & 20 & 34 \\
No. Container & & A-1 & A-2 & A-3 \\
\hline Berat tanah Basah + Container,W1 & Gram & 21.88 & 21.4 & 22.3 \\
Berat tanah Kering + Container,W2 & Gram & 19.95 & 19.14 & 20.79 \\
Berat Container, W3 & Gram & 13.63 & 13.14 & 14.18 \\
Berat Air (Ww = W1-W2) & Gram & 1.93 & 2.26 & 1.51 \\
Berat tanah Kering,(Wd= W2 - W3) & Gram & 6.32 & 6 & 6.61 \\
Kadar Air, Ww/Wd x 100\% & $\%$ & 30.54 & 37.66 & 22.84 \\
\hline \multicolumn{5}{c}{ Sumber : Hasil Perhitungan }
\end{tabular}


Tabel 3. Batas Susut Tanah Yang Diuji

\begin{tabular}{lcc}
\hline No.Test & - & 1 \\
\hline Berat mould, W1 & Gram & 20.47 \\
Berat mould + Tanah basah,W2 & Gram & 48.31 \\
Berat mould + Tanah Kering,W3 & Gram & 40.28 \\
Berat air raksa yang di pakai untuk mengisi mangkok shringkage,W4 & Gram & 378 \\
Berat air raksa yang di pindahkan oleh tanah yang ditest,W5 & Gram & 152.73 \\
Berat tanah basah,Ww=W2-W1 & Gram & 27.84 \\
Berat tanah Kering,Wd=W3-W1 & Gram & 19.81 \\
Berat air,Wa=W2-W3 & Gram & 8.03 \\
Berat Jenis air Raksa, r & & 13.6 \\
Volume Tanah Basah, Vw =(W4)/r & $\mathrm{m}^{3}$ & 27.80 \\
Volume Tanah Basah, Vd =(W5)/r & $\mathrm{m}^{3}$ & 11.23 \\
Kadar air, = Wa/Wd x 100 \% & $\%$ & 40.53 \\
Batas Susut, SL & $\%$ & 43.11 \\
\hline
\end{tabular}

C. Pemeriksaan Analisa Saringan

Sumber : Hasil Perhitungan

Pemeriksaan ini dimaksudkan agar dapat mengetahui cara menentukan ukuran butiran dan susunan butiran ( gradasi ) tanah yang tertahan saringan no.200. Tujuan dari pemeriksaan ini untuk mengklarifikasikan dan mengelompokkan jenis tanah yang lolos dan tertahan saringan no.200 agar mudah menganalisis distribusi ukuran butir tanah.

Tabel 4. Analisa Saringan Sampel Tanah Yang Diuji

\begin{tabular}{cccccc}
\hline sieve & Diameter & Berat & Komulatif & \multicolumn{2}{c}{ Persen $(\%)$} \\
No. & $(\mathrm{mm})$ & Tertahan $(\mathrm{gr})$ & $(\mathrm{gr})$ & Tertahan & Lolos \\
\hline 4 & 453 & 1.2 & 1.2 & 0.50 & 99.50 \\
10 & 432 & 47.52 & 48.72 & 20.40 & 79.60 \\
40 & 413 & 127.85 & 176.57 & 73.90 & 26.10 \\
100 & 414 & 41.77 & 218.34 & 91.49 & 8.51 \\
200 & 399 & 12.37 & 230.71 & 96.56 & 3.44 \\
Pan & 377 & 8.2 & 238.91 & 100.00 & 0.00 \\
\hline
\end{tabular}

\section{Sumber : Hasil Perhitungan}

D. Pemeriksaan Hidrometer

Pemeriksaan ini dimaksudkaan agar dapat mengatahui cara menentukan ukuran dan susunan butiran ( gradasi ) tanah yang lolos saringan no.200. Tujuan dari pemeriksaan ini adalah untuk mengatahui distribusi ukuran-ukuran dan susunan butiran ( gradasi ) tanah yang lolos saringan no.200.

Tabel 5. Analisa Saringan dan Bentuk Butiran Sampel Tanah Yang Diuji

\begin{tabular}{|c|c|c|c|c|c|c|c|c|}
\hline $\begin{array}{l}\text { Waktu } \\
\text { (menit) }\end{array}$ & $\begin{array}{c}\mathrm{T} \\
\left({ }^{\circ} \mathrm{C}\right)\end{array}$ & $\mathrm{R}$ & Rcp & $\begin{array}{c}\% \text { Butiran } \\
\text { Halus } \\
\text { a.Rcp/Ws x } \\
100 \%\end{array}$ & $\mathrm{Rcl}$ & $\begin{array}{c}\mathrm{L} \\
(\mathrm{cm})\end{array}$ & K & $\begin{array}{l}\mathrm{D}=\mathrm{K} \\
(\mathrm{L} / \mathrm{t})^{0,5}\end{array}$ \\
\hline 0.25 & 29 & 55 & 63.05 & 115.60 & 56 & 6.70 & 0.01290 & 0.06678 \\
\hline 0.5 & 29 & 50 & 58.05 & 106.42 & 51 & 6.50 & 0.01290 & 0.04651 \\
\hline 1 & 29 & 46 & 54.05 & 99.10 & 47 & 6.60 & 0.01290 & 0.03314 \\
\hline 2 & 29 & 37 & 45.05 & 82.60 & 38 & 7.30 & 0.01290 & 0.02465 \\
\hline 4 & 29 & 27 & 35.05 & 64.25 & 28 & 7.80 & 0.01290 & 0.01801 \\
\hline 8 & 29 & 26 & 34.05 & 62.42 & 27 & 8.80 & 0.01290 & 0.01353 \\
\hline 15 & 29 & 25 & 33.05 & 60,60 & 26 & 9.10 & 0.01290 & 0.01005 \\
\hline
\end{tabular}




\begin{tabular}{ccccccccc}
30 & 29 & 24 & 32.05 & 58.75 & 25 & 9.70 & 0.01290 & 0.00734 \\
60 & 29 & 23 & 31.05 & 56.92 & 24 & 10.40 & 0.01290 & 0.00537 \\
90 & 29 & 22 & 30.05 & 55.10 & 23 & 10.70 & 0.01290 & 0.00445 \\
120 & 29 & 22 & 30.05 & 55.10 & 23 & 10.80 & 0.01290 & 0.00387 \\
240 & 29 & 20.5 & 28.55 & 52.34 & 21.5 & 11.40 & 0.01290 & 0.00281 \\
1440 & 29 & 20 & 28.05 & 51.42 & 21 & 12.90 & 0.01290 & 0.00122 \\
\hline
\end{tabular}

E. Pemadatan / Compaction

Pemeriksaan ini dimaksudkan agar dapat mengetahui cara menentukan kadar air optimum dari beberapa \% air. Tujuan pemadatan di laboratorium adalah usaha untuk mendapatkan kepadatan tanah maksimum pada energy yang standar, dengan jalan memberikan kadar air optimum.

Tabel 6. Hasil Pembacaan tanah + container

\begin{tabular}{|c|c|c|c|c|}
\hline Berat tanah + container & \multicolumn{4}{|c|}{27,78} \\
\hline Berat Container & \multicolumn{4}{|c|}{14,25} \\
\hline Berat tanah basah & \multicolumn{4}{|c|}{2500} \\
\hline Berat tanah basah & \multicolumn{4}{|c|}{13,53} \\
\hline Tanah kering & \multicolumn{4}{|c|}{11,87} \\
\hline Penambahan air \% & 50 & 40 & 30 & 20 \\
\hline Penambahan air cc & 161,52 & 242,8 & 100 & 30 \\
\hline Kadar air & 1,66 & & & \\
\hline Persen kadar air & $=\frac{1,66}{11,87}$ & & & \\
\hline Kadar air \% & \multicolumn{4}{|c|}{13,98} \\
\hline
\end{tabular}

Tabel 7. Hasil Pembacaan tanah + mould

$\begin{array}{ccccc}\text { Berat tanah + Mould } & 5529 & 5621 & 5593 & 5644 \\ \text { Berat mould } & 3900 & 3900 & 3900 & 3900 \\ \text { Berat tanah basah } & 1629 & 1721 & 1693 & 1744 \\ \text { Berat isi basah } \gamma_{\mathrm{w}} & 1,74 & 1,84 & 1,82 & 1,87 \\ \begin{array}{c}\text { Berat isi kering } \\ \gamma_{\mathrm{dw}} \mathrm{X}_{100}\end{array} & 1,46 & 1,47 & 1,43 & 1,43\end{array}$

\begin{tabular}{lcccc}
\hline Tabel 8. Kadar Air \% & \multicolumn{3}{c}{32,04} & 32 \\
\hline Tanah basah + container & 28,17 & 30,79 & 32,97 & 27,66 \\
Tanah kering + container & 25,95 & 27,28 & 27,97 & 4,34 \\
Berat air & 2,22 & 3,51 & 4,07 & 13,21 \\
Berat container & 14,3 & 13,1 & 12,94 & 14,45 \\
Tanah kering & 11,65 & 14,18 & 15,05 & 30,03 \\
Kadar air (W) \% & 19,06 & 24,75 & 27,04 & \multicolumn{5}{c}{ Sumber : Hasil Perhitungan }
\end{tabular}

F. Pemeriksaan CBR Tanah Asli

Pemeriksaan ini dimaksudkan untuk mengetahui nilai daya dukung tanah dalam kepadatan maksimum.

Tabel 9. Hasil CBR Tanah Asli

\begin{tabular}{|c|c|c|c|c|c|c|}
\hline \multicolumn{7}{|c|}{ Harga CBR } \\
\hline CBR & 1.62 & $\%$ & \multicolumn{2}{|c|}{$0.1 "$} & \multicolumn{2}{|c|}{$0.2^{\prime \prime}$} \\
\hline \multicolumn{2}{|c|}{ Atas } & & $\begin{array}{c}49.20 \\
3 \times 1000 \\
\mathbf{1 . 6 4}\end{array}$ & $\begin{array}{c}\mathrm{x} 100 \% \\
\%\end{array}$ & $\begin{array}{c}71.61 \\
3 \times 1500 \\
\mathbf{1 . 5 9}\end{array}$ & $\begin{array}{c}\mathrm{x} 100 \% \\
\%\end{array}$ \\
\hline & vah & & $3 \times 1000$ & x $100 \%$ & $3 \times 1500$ & x $100 \%$ \\
\hline
\end{tabular}


Sumber : Hasil Perhitungan

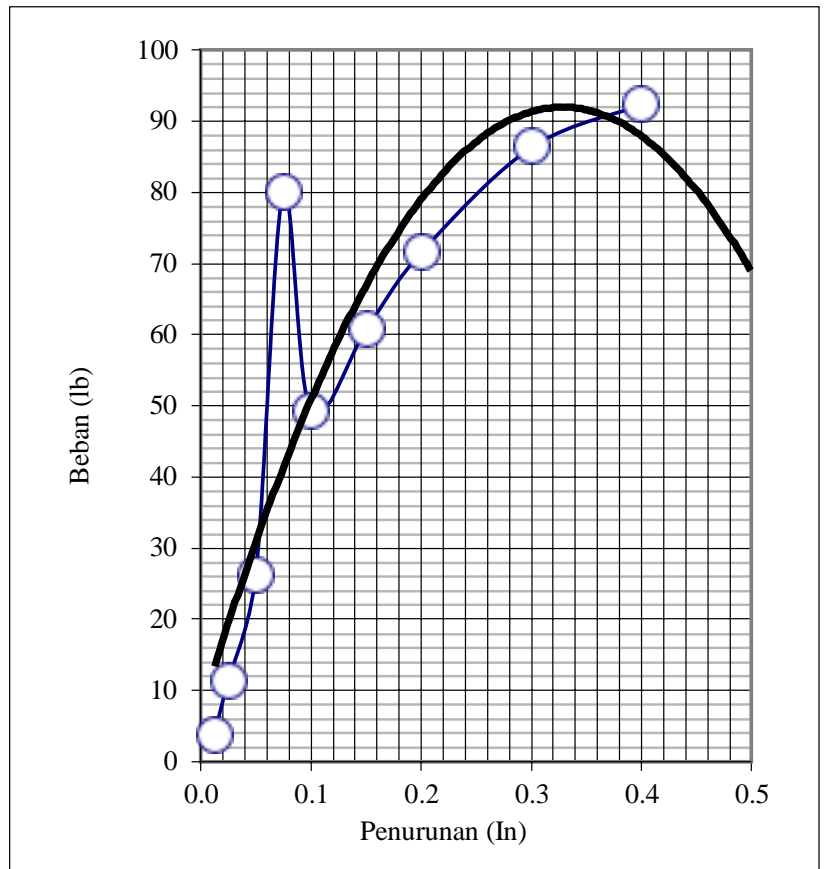

Gambar 1. Grafik Penurunan dan Pembebanan CBR Tanah

G. Pemeriksaan CBR Tanah +Semen

Pemeriksaan ini dimaksudkan untuk mengetahui nilai daya dukung tanah dalam kepadatan maksimum.

Tabel 9. Hasil CBR Tanah Asli

\begin{tabular}{|c|c|c|c|c|c|c|}
\hline \multicolumn{7}{|c|}{ Harga CBR } \\
\hline CBR & 3.76 & $\%$ & \multicolumn{2}{|c|}{$0.1^{\prime \prime}$} & \multicolumn{2}{|c|}{$0.2^{\prime \prime}$} \\
\hline \multirow{2}{*}{\multicolumn{2}{|c|}{ Atas }} & & 129.89 & x $100 \%$ & 143.37 & x $100 \%$ \\
\hline & & & 4.33 & $\%$ & 3.19 & $\%$ \\
\hline \multicolumn{2}{|c|}{ Bawah } & & $3 \times 1000$ & x $100 \%$ & $3 \times 1500$ & x $100 \%$ \\
\hline
\end{tabular}

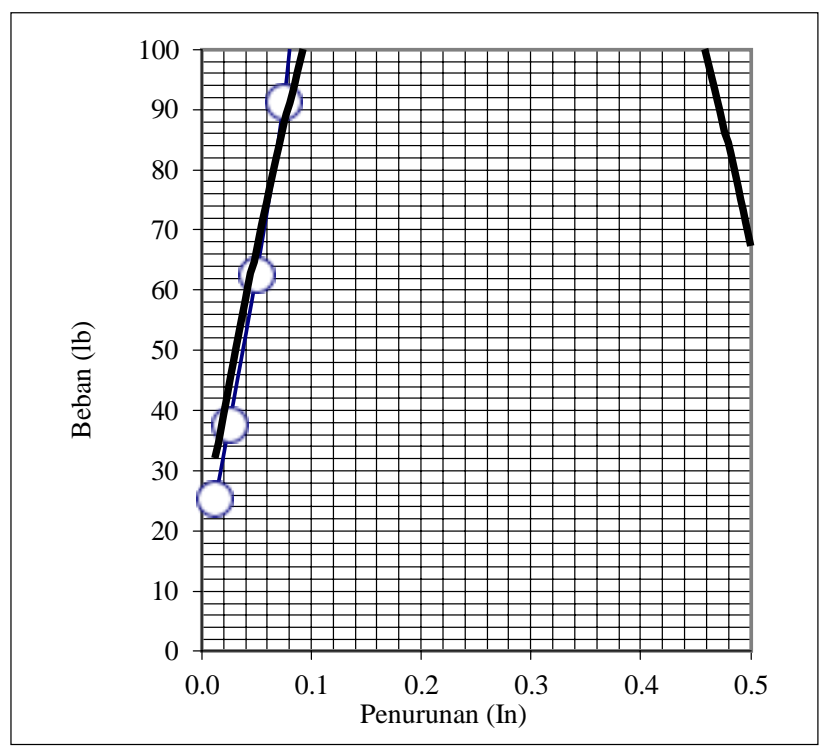

Gambar 2. Grafik Pengaruh Portland Cement type I Terhadap Nilai CBR dengan Pemeraman 3 Hari 


\section{KESIMPULAN}

Berdasarkan analisa data dan pembahasan sebelumnya, maka dapat disimpulan bahwa :

1. Sifat-sifat indeks (index properties) menunjukkan sifat-sifat tanah yang megindikasikan jenis dan kondisi tanah, serta memberikan hubungan terhadap sifat-sifat mekanis seperti kekuatan dan pemampatan atau kecenderungan untuk memgembang, adapun sifat indeks tanah menunjukkan Berat Jenis Spesifik $(\mathrm{Gs})=36,88 \%$, Indeks Plastisitas (batas cair) $=17,49 \%$, Batas Susut $(\mathrm{SL})=$ $43,11 \%$, dan Analisa Saringan lolos saringan no $200=3,44 \%$ dan yang tertahan $=96,56 \%$ dalam penelitian ini tanah yang digunakan jenis tanah lempung dimana tanah lempung merupakan agregat partikel-partikel berukuran mikroskopik dan submikroskopik yang berasal dari pembusukan kimiawi unsur-unsur penyusun batuan.

2. Hasil penelitian menunjukkan bahwa nilai CBR, dan kepadatan standar naik dengan nai knya presentase semen didalam tanah. Pada kadar semen tersebut terlihat adanya penurunan potensi pengembangan dan peningkatan nilai CBR yang cukup signifikan. Pada pengujian tekan bebas terlihat bahwa semakin tinggi kadar semen, nilai parameter kuat geser tanah semakin naik. Penambahan semen telah mengingkatkan nilai daya dukung tanah secara singnifikan. Nilai CBR semakin naik jika seiring dengan penambahan semen, dimana nilai CBR tanah asli sebesar 1,62 $\%$. Terjadinya peningkatan nilai CBR pada campuran optimum $7 \%$ semen dengan waktu pemeraman 3 hari dengan nilai CBR 3,76\%.

\section{DAFTAR PUSTAKA}

Budi, G. S. (2011). Pengujian Tanah Di Laboratorium (Penjelasan Dan Panduan). Yogyakarta: Graha Ilmu.

M.Eng, D. I. (2010). Stabilitasi Tanah Untuk Perkerasan Jalan. Yogyakarta: Gajah Mada University Press.

Purnomo, I. S. (1989). Mekanika Tanah Jilid II. Malang: Penerbit Kanisius.

Soedarmo, I. G. (1989). Mekanika Tanah Jilid II. Malang: Fakultas Teknik Universitas Katolik Widya Karya Malang.

Sutarman, E. (2013). Konsep Dan Aplikasi Mekanika Tanah. Yogyakarta: Andi Yogyakarta.

Standar Nasional. (1994).Tata cara Pembuatan Satabilisasi Tanah dengan Semen Porland untuk Jalan (SNI-3438-1994).Jakarta.

Tergazhi, D. I. (1993). Mekanikah Tanah. Malang. 